\title{
A nova reforma do ensino médio amparada pela Lei 13.415 e suas ameaças para a disciplina de educação física
}

\author{
The new reform of high school supported by the Law 13.415 and its threats to the \\ discipline of physical education
}

\author{
Bruna Beatriz da Rocha ${ }^{1}$ \\ Márcio Norberto Farias ${ }^{2}$
}

\begin{abstract}
Resumo
Este estudo parte da preocupação com o debate sobre as mudanças propostas na reforma do Ensino Médio e seus possíveis impactos sobre a Educação Física. Nesse sentido, o recorte a ser realizado no trabalho busca esboçar uma interpretação sobre a lei 13.415, que se volta para o Ensino Médio em um processo que afeta a formação humana em meio às políticas educacionais e as propostas pedagógicas existentes. Pretende-se construir uma reflexão teórica para verificar a literatura produzida sobre o tema, especialmente aquelas obras que servem de subsídio para as proposta pedagógicas disponíveis dentro da Educação Física voltadas para o Ensino Médio. Com isso, espera-se obter respostas suficientes que contribuam para o esclarecimento do impacto da Nova Reforma do Ensino Médio em face de um contexto que tende a flexibilizar a educação, o que se relaciona diretamente com a conjuntura capitalista do século XXI.
\end{abstract}

Palavras-chave: Educação Física Escolar; Reforma; Novo Ensino Médio.

\begin{abstract}
This study starts from the concern with the debate about the proposed changes in the reform of High School and its possible impacts on Physical Education. In this sense, the cut to be made in the work seeks to outline an interpretation of Law 13,415 that turns to high school in a process that affects human formation in the midst of educational policies and existing pedagogical proposals. It is intended to build a theoretical reflection to check the literature produced on the subject, especially those works that serve as a basis for the pedagogical proposals available within Physical Education aimed at high school. With this, it is expected to obtain sufficient answers that contribute to clarify the impact of the New High School Reform in the face of a context that tends to make education more flexible, which is directly related to the 21 st century capitalist conjuncture.

\footnotetext{
1 Mestra em Educação pela Universidade Federal de Lavras (UFLA), Pós-graduanda em Didática e Trabalho Docente pelo Instituto Federal do Sudeste de Minas Gerais - Campus São João Del-Rei, Professora da rede privada e membra do grupo de Pesquisas em Teoria Crítica e Educação da Universidade Federal de Lavras (UFLA). E-mail: bruuna_rocha1@ @otmail.com

2 Doutor em Sociologia pela Universidade Estadual Paulista Júlio de Mesquita Filho/Campus Araraquara, com pós-doutoramento em Filosofia da Educação na Universidade de Leipzig (Alemanha). Docente do Departamento de Educação Física na Universidade Federal de Lavras, Lavras, Minas Gerais, Brasil.
} 
Keywords: School Physical Education; Reform; New High School.

\section{Introdução}

De acordo com a mudanças sociais, históricas e culturais, os conteúdos disciplinares também sofrem transformações e, com a Educação Física não é diferente. O impacto dessas mudanças pode ser observado na história dos currículos institucionais, nas práticas pedagógicas e nos documentos oficiais que regem a estrutura e o funcionamento do sistema escolar como um todo.

Nas aulas da disciplina é possível notar uma mudança no cenário da Educação Física, o que antes era caracterizado pela perspectiva do fazer prático irrefletido está, aos poucos, assumindo um caráter científico, isto é, um diálogo cada vez mais acentuado entre o saber científico expresso nas teorias pedagógicas da educação, tomando por base o planejamento, as diretrizes básicas, a linha de ensino e as expectativas da comunidade. Nesse sentido, um exemplo é nova Reforma do Ensino Médio.

A nova Reforma do Ensino Médio traz com ela inúmeros desafios para a Educação e, em especial, como tratamos neste trabalho, para a disciplina de Educação Física. Entender o que está acontecendo atualmente não é uma tarefa fácil, pois o campo está em disputa. Neste contexto, o recorte realizado para este artigo, busca problematizar as possíveis implicações da lei 13.415 na educação, e em especial na disciplina de Educação Física, revelando aspectos que compõem a nova política educacional brasileira.

\section{Método}

O método proposto para o estudo será uma pesquisa teórica e possuirá como característica uma análise de natureza qualitativa, que de acordo com Turato (2003), caracteriza-se principalmente pela profundidade de análise. A pesquisa de natureza qualitativa se preocupa basicamente com significados, opiniões e representações acerca de determinado fenômeno.

O arranjo metodológico do trabalho será fundamentado por meio de análise textual discursiva. Para Moraes e Galiazzi (2006, p.118), “a análise textual discursiva é uma abordagem de análise de dados que transita entre duas formas consagradas de análise na pesquisa qualitativa, que são a análise de conteúdo e a análise de discurso.’. Dessa forma, a 
partir das hipóteses criadas através dos problemas encontrados, haverá uma associação composta por ideias e pensamentos na busca pela solução. O início do processo da análise textual discursiva é a desmontagem dos textos também nomeado como unitarização, caracterizado por leituras cuidadosas do corpus e também examinação cautelosa dos textos e leis em seus detalhes, fragmentando-os no sentido de atingir unidades constituintes, enunciados referentes aos assuntos pesquisados. A junção de significados semelhantes em distintos materiais, diante de um mesmo fenômeno, é responsável por construir a segunda fase da análise intitulada como categorização, destaca-se nesta fase que a interpretação do pesquisador é fundamental para a análise. A terceira e última fase é caracterizada como comunicação, neste período é ressaltado a importância à fidedignidade junto ao corpus, além disso, representa o intenso esforço empreendido nas fases anteriores realizando a montagem de dados.

Dessa forma, a escolha por esta análise de dados se dá por possibilitar uma autonomia ativa, organizando os pensamentos precedentes, avaliando, comunicando, reconstruindo e expondo para os leitores um vigente e efetivo conhecimento.

\section{Resultados}

Presenciamos com frequência o açodamento na emissão de leis sob a forma de decretos e medidas provisórias após o impeachment da presidente Dilma Rousseff, que desencadeou no comando do presidente Michel Temer, entre elas, destaca-se a lei 13.415 da Nova Reforma do Ensino Médio que foi o primeiro ato direto do governo Temer no cenário educacional brasileiro (LINO, 2017).

Os autores Oliveira e Costa (2017) trouxeram afirmações importantes sobre a nova lei:

No ano de 2016, em que a Lei de Diretrizes e Bases da Educação Nacional (LDBEN n ${ }^{\circ}$ 9.394/1996) completou duas décadas de sua publicação, este importante marco da democratização da educação no Brasil recebeu a proposta mais contundente de mudança na estrutura educacional brasileira: a reforma do ensino médio, por meio da MP $\mathrm{n}^{\circ} 746$, de 22 de setembro de 2016 (OLIVEIRA; COSTA, 2017, p. 3).

A partir da promulgação da Medida Provisória n 746 de 22 de setembro de 2016 no governo do presidente Michel Temer, surge à lei 13.415/17 elaborando propostas de um novo Ensino Médio. Observa-se o interesse em criar mudanças metodológicas e conceituais 
específicas na fase final da educação básica. Desta forma, a nova lei visará suprir interesses do mercado de trabalho e também necessidades impostas pelos setores empresariais. "Assim, a lógica do mercado se insere no campo da educação para que possa operar à sua semelhança e expectativa do chamado mercado financeiro, e a partir desses interesses a atual Reforma do Ensino Médio ignora a formação humana e social desses indivíduos” (SANTOS; SOUZA, 2018, p. 251).

Desse modo, os Reformadores Empresariais e o Movimento pela Base Nacional Comum Curricular possuem grandes influências no Novo Ensino Médio. Eles afirmam que o novo Ensino Médio será mais atrativo e poderá evitar os níveis de evasão e melhorar a qualidade do ensino, uma vez que os números apontam as médias e os rankings elaborados a partir das notas alcançadas nas provas realizadas no Ensino Médio, em que o currículo é "pouco atrativo", o que aumenta o índice de evasão escolar nesse período. Além disso, é nítido a intenção de atender as demandas do mercado de trabalho oferecendo preparação de mão de obra.

O autor Frizzo (2016), traz uma reflexão importante ao afirmar que essa discussão está atravessada por problemáticas oriundas dos profissionais da educação, das entidades sindicais e também de movimentos estudantis. Assim sendo, destaca-se o fato da questão não ter passado por um amplo debate nas escolas e também nas comunidades, é concretizada por intermédio de uma referência de especialista que trata do conhecimento escolar, também há um questionamento no conteúdo da Base Nacional Comum Curricular (BNCC), pois de acordo com as suas demandas e suas necessidades desrespeitam a autonomia das escolas para elaboração de currículos e projetos pedagógicos.

A nova proposta de Ensino Médio foi realizada via uma Medida Provisória² (MP). A MP empregue pelo presidente da República, é utilizada em casos de urgência e relevância, sendo um instrumento que produz efeitos imediatos e possui a força de uma lei.

O uso da medida provisória caracteriza uma forma autoritária de legislar, que sinaliza o desprezo pelo necessário diálogo acadêmico e legislativo, típico de um regime de exceção. A alteração da LDB de forma açodada,

\footnotetext{
${ }^{2}$ A Medida Provisória (MP) possui um prazo de vigência de sessenta dias, podendo se estender apenas uma vez por sessenta dias. A MP caso não aprovada dentro de 45 dias, contados desde a sua publicação, é trancada a pauta até que seja votada. Sendo assim, a Câmara só pode votar alguns tipos de proposição em sessão extraordinária.
} 
sem o debate sobre os impactos que a Reforma produzirá a médio e longo prazo, pode ser considerada, no mínimo, como irresponsável e inadequada, e compromete a oferta de qualidade desse nível de ensino (LINO, 2017, p.77).

Em síntese, com apoio de setores ligados ao capital como empresas que visam uma formação rápida e prática para o Novo Ensino Médio, foi aprovada a lei 13.415 por meio de uma Medida Provisória, indo de encontro com as reivindicações e interesses das entidades científicas, dos jovens estudantes, e dos organismos de classe, que procuram resistir aos ataques aos direitos, em especial, na educação (MATOS, 2019).

Por conseguinte, diferentes entidades vêm se manifestando contra a aplicação da nova proposta de Reforma do Ensino Médio, por entenderem que ela traz prejuízos à formação dos estudantes e afeta o trabalho na área pedagógica da Educação Física. Os autores Santos, Santos Junior e Almeida Ferreira (2017), explicitam que no campo da Educação Física entidades como a Executiva Nacional dos Estudantes de Educação Física (ExNEEF), o Colégio Brasileiro de Ciência do Esporte (CBCE), Movimento Nacional Contra a Regulamentação do Profissional de Educação Física (MNCR) o Conselho Federal de Educação Física (CONFEF), dentre outros, também apresentam críticas à nova reforma.

Um grupo de representantes do Colégio Brasileiro de Ciência do Esporte, preocupados com a defesa da Educação Física como componente curricular obrigatório no Ensino Médio, entregou um documento nomeado "Carta aberta do Fórum em defesa da Educação Física ao Congresso Nacional Brasileiro" ao Presidente da subcomissão do desporto da câmara dos deputados e membro da comissão mista da MP 746/2016, justificando os motivos e importâncias pela qual a disciplina deve-se manter no currículo. Destacamos um dos trechos:

Quando se flexibiliza o currículo do Ensino Médio, alocando a Educação Física para um componente curricular optativo, coloca-se em risco o direito de aprendizagem dos alunos de experimentar os esportes, de usufruir e apropriar-se dos vários tipos de danças, o prazer de jogar e brincar na escola, refletir sobre as ações ocorridas nos esportes coletivos, a construção de valores oportunizados pelo acesso às várias lutas do Brasil e do mundo, analisar com propriedade os vários tipos de ginásticas, compreender os cuidados que se deve adotar nas práticas corporais de aventura e, assim, tolhendo o protagonismo estudantil perante as práticas corporais em sua comunidade (CBCE, 2016, p.1).

Assim, consideramos que, a partir do documento apresentado, as modificações 
estabelecidas para o novo Ensino Médio estão em desacordo com as necessidades dos estudantes na sociedade em que vivemos. Tudo indica que haverá uma negação acerca dos conhecimentos da disciplina de Educação Física que são promovidos dentro dos espaços escolares. Compartilhamos da defesa que em quaisquer propostas de Ensino Médio que se queira almejar, a Educação Física deve ser mantida obrigatoriamente nas escolas.

Ainda nesse sentido, a Executiva Nacional dos Estudantes de Educação Física (2016), complementa afirmando que há anos não se viam um retrocesso quanto ao que estamos sofrendo no momento. Haveria equívocos e dissociações nessa Reforma ao mirar-se em uma formação meramente técnica e voltada exclusivamente ao mercado de serviços, indicando que a formação humanizadora não seria mais uma prioridade. Ao que tudo indica, para os representantes do atual governo, uma educação técnica que beneficia os grandes empresários deste país exige que a reforma ofereça um tipo de formação profissional que atenda o mercado com a mão de obra barata dos trabalhadores. Além disso, um possível entendimento é que a Nova Reforma desconsideraria a necessidade de conhecimentos reflexivos e questionadores acerca da história, da linguagem e também da cultura para transformar as condições sociais brasileiras.

A Educação Física como se pode ver nos pressupostos apresentados até o momento, nunca foi assegurada por proporcionar tal formação humanizadora. Sua retirada talvez indique que apesar de todos os elementos que possui e que a justificam como de interesse do mercado, não fazem frente a outros elementos que a concernem em que acabam por se contrapor a lógica neoliberal: elementos que se caracterizam por propiciar uma vivência lúdica, com o mundo.

Como primeiro momento, a disciplina de Educação Física havia sido descartada do currículo com a nova lei. Tendo em vista a enorme repercussão negativa de estudiosos da área educacional e também sob pressão da sociedade, o governo revogou o texto final da lei, de forma que a disciplina manteve-se como um componente curricular obrigatório da educação básica. Embora a Educação Física tenha sido contemplada na nova redação, sendo reinserida novamente nos currículos, ainda assim a mesma foi afetada, isto porque as disciplinas de Educação Física, Artes, Sociologia e Filosofia aparecem com os termos "estudos e práticas" como nos apresenta a lei em seu artigo 35 " $§ 2^{\circ}$ "a Base Nacional Comum Curricular referente ao ensino médio incluirá obrigatoriamente estudos e práticas de educação física, arte, sociologia e filosofia.” (BRASIL, 2017, p.1 ). Isso posto, as autoras Ramos e Heinsfeld 
(2017, p. 18.205), relatam que "essa construção abre brecha para o questionamento de que esses conteúdos podem ser estudados e praticados, mas não necessariamente formalmente ensinados".

Neste sentido, Júnior et.al (2017), complementam este pensamento nos mostrando que:

O texto, da forma como está descrito, abre espaço para discussões reduzidas que não abrangem a totalidade dos conhecimentos que cada área disciplinar possui e através da qual os alunos têm direito a aprender. Na prática se poderá utilizar os "estudos e práticas" das disciplinas, que o dispositivo legal menciona, somente como temas que podem ser discutidos por outras disciplinas (JÚNIOR et.al, 2017, p. 1172).

Dessa maneira, a Educação Física além de não ser configurada pela nova reforma tal como as disciplinas formais, por exemplo: Português, Inglês e Matemática, a disciplina se encontrará ainda mais enfraquecida e desvalorizada com a Nova Reforma. Entendemos que a desvalorização da matéria no currículo remete ao retrocesso que vai muito além dos conteúdos englobando também a formação pessoal dos jovens conforme visto nesta citação:

Nessa conjuntura, a Educação Física que historicamente foi responsável pelo desenvolvimento da aptidão física dos alunos, e até então se colocava como disciplina fundamental, no projeto de formação humana, do capital, perde centralidade. Posto que a formação do trabalhador é balizada por disciplinas que atuam no campo cognitivo e interacional, sendo assim, essa prática pedagógica não contribui ao menos imediatamente para o atual projeto de formação humana hegemônico (COIMBRA, 2009, p.49).

Os pesquisadores Ramos e Frigotto (2016), alegam que as novas propostas com a Reforma introduzem uma agressão quanto à dura conquista do Ensino Médio como educação básica universal. Há também uma agressão frontal à Constituição de 1988 e à Lei de Diretrizes e Bases da Educação Nacional, que garantem a universalidade do Ensino Médio como etapa final de educação básica a todos que têm direito.

Ao prosseguir com a análise da disciplina de Educação Física, observa-se que, com a reforma, os jovens teriam a possibilidade de optar por currículos flexíveis a partir dos itinerários formativos. Teixeira et. al (2019), nos apresentam que sessenta por cento da composição do currículo será composta por conteúdos mínimos obrigatórios que será definida pela BNCC. Os outros quarenta por cento restantes serão abrangidos pelos 
itinerários formativos, na qual, os alunos escolherão entre as cinco áreas de conhecimento citadas na Lei 13.415 (Linguagens e suas Tecnologias, Matemática e suas Tecnologias, Ciências da Natureza e suas Tecnologias, Ciências Humanas e Sociais Aplicadas e Formação Técnica e Profissional). Dessa maneira, a Educação Física só irá compor algo em torno de no máximo quarenta por cento da formação dos alunos, pois ela estaria enquadrada na área de Linguagens e suas Tecnologias junto às disciplinas de Artes, Inglês e Português. A BNCC ao citar a disciplina de Educação Física, afirma que:

Na BNCC para o Ensino Médio, a abordagem integrada da cultura corporal de movimento na área de Linguagens e suas Tecnologias aprofunda e amplia o trabalho realizado no Ensino Fundamental, criando oportunidades para que os estudantes compreendam as inter-relações entre as representações e os saberes vinculados às práticas corporais, em diálogo constante com o patrimônio cultural e as diferentes esferas/campos de atividade humana. Tratar de temas como o direito ao acesso às práticas corporais pela comunidade, a problematização da relação dessas manifestações com a saúde e o lazer ou a organização autônoma e autoral no envolvimento com a variedade de manifestações da cultura corporal de movimento permitirá aos estudantes a aquisição e/ou o aprimoramento de certas habilidades. Assim, eles poderão consolidar não somente a autonomia para a prática, mas também a tomada de posicionamentos críticos diante dos discursos sobre o corpo e a cultura corporal que circulam em diferentes campos da atividade humana (BRASIL, 2017, p. 475).

Isto posto, concordamos com Matos (2019), quando afirma que a BNCC faz uso indiscriminado de conceitos como corporeidade e cultura corporal, sem a devida referência ou fundamentação. Ela destaca a concepção de linguagem corporal enquanto objeto, o que dá a entender que os referidos conceitos estariam compreendidos no quadro conceitual de linguagem corporal, de outra forma, a opção por esse objeto se relacionada com a tentativa de integrar os conhecimentos vinculados ao componente curricular de Educação Física aos demais da área de Linguagem e suas Tecnologias.

Não obstante, há outra questão que necessita ser mais bem refletida: se os jovens escolherem as outras áreas disponíveis que concorrem entre si estarão obsoletos dos conhecimentos sobre a Educação Física. Como afirmam os autores Santos, Santos Junior e Almeida Ferreira (2017), caso o aluno opte pela Educação Profissional, o mesmo não obteria sequer os conhecimentos da Educação Física pelo fato da disciplina constar em área distinta da que ele escolheu.

A escritora Oliveira (2019), nos mostra que, com a nova proposta de itinerários, 
poderá haver um agravamento da desigualdade dentro do processo educacional, uma vez que caberá aos sistemas de ensino de acordo com as pressões recebidas daqueles que, por sua vez estão pressionados a entrar no mercado de trabalho, resolver os termos dos itinerários formativos que irão ofertar. Isso geraria distorções ainda mais graves que poderiam ampliar as injustiças sociais e econômicas, porque quanto mais carente for à escola do estudante, menores seriam as suas oportunidades, o que representaria a manutenção e reprodução das desigualdades sociais que afligem o país. E pior, enquanto os estudantes mais carentes não terão mais acesso a alguns conteúdos que atualmente são obrigatórios para todos, de outro lado o Estado dispensa-se do dever de garantir o acesso à tais direitos.

Em relação ao trabalho docente, também observamos marcas da flexibilização e da precarização. De acordo com a lei em seu artigo $6^{\circ}, \mathrm{O}$ artigo. 61 da Lei $\mathrm{n}^{\circ}$ 9.394, de 20 de dezembro de 1996, passou a vigorar com algumas alterações, sendo assim, torna-se possível a contratação de profissionais com o "notório saber", na qual, é restrita ao quinto itinerário formativo denominado "educação profissional técnica" e determina que esses profissionais poderão ministrar conteúdos de áreas afins à sua formação ou experiência profissional.

A suposta contratação de professores com o "notório saber" implicaria admitir que vários profissionais sem a formação pedagógica que as licenciaturas proporcionam, criando a possibilidade de realização de pesquisa como base da formação, poderão se colocar à disposição de trabalhos mesmo obtendo remunerações menores que aquela prevista pelo piso salarial docente, o que demonstra o papel da legislação no sentido de acentuar ainda mais a concorrência a partir da produção de excedente - empregados ou subempregados. Em vista disso, há outro risco, as lutas da categoria docente obtida por meio de uma longa história de conflitos e tensões poderiam ser desconsideradas e mesmo iniciar um desmonte nessa nova Reforma.

Os autores Gomide e Jacomeli (2017), evidenciam que embora o notório saber esteja restrito à educação profissional, é necessário a compreensão de que o exercício da docência não se limita ao domínio de conteúdos de áreas afins à formação ou experiência profissional. Para exercer a profissão “professor” é imprescindível, além de dominar o conteúdo das diversas áreas de conhecimento, a didática e o entendimento de como se dá o processo de ensino-aprendizagem.

Isso é corroborado por Antunes (2000). Para ele trata-se de uma aguda destruição que no fundo é a expressão da crise estrutural que assola a (des)sociabilização contemporânea. 
Sendo assim, ao destruir a força humana de quem trabalha, destroem-se também os direitos sociais, brutalizando homens e mulheres que vivem do trabalho, tornando-se predatória a relação entre a natureza e a produção. Desta forma, se mantém o circuito reprodutivo de exploração do capital.

A respeito do trabalho docente, Oliveira (2004), ainda enfatiza que as várias mudanças ocorridas nas relações de trabalho e emprego são caracterizadas pelo fenômeno, considerado por alguns escritores, da precarização das relações de trabalho, marcada pela intensificação da concorrência pela relação de um contra o outro. Esse movimento conflituoso, contudo, implica numa relação de emprego que tentam flexibilizar na legislação trabalhista com vistas a promover a desregulamentação do setor.

Se, para o novo Ensino Médio, o reconhecimento do notório saber contribui para a destituição da formação docente na Universidade Pública, então esta proposta iria contra as lutas para que a docência seja exercida unicamente por profissionais formados em cursos de licenciatura voltados exclusivamente para a formação de professores. Ainda assim, conforme a autora Costa (2018) afirma, para a educação básica, o notório saber remete ao primórdios do século XIX. Naquele período, a educação estava a mercê do aprendizado de técnicas, através de profissionais dos ofícios, era uma educação precária para os pobres. Hoje, a Universidade se expandiu mas é preciso retirar das pessoas a gana de nela se formar.

Ainda neste esforço de compreendermos esse processo de desvalorização da Educação Física Escolar, que busca colocar em segundo plano os conhecimentos relacionados com as áreas de ciências humanas, parece implícito uma revalorização dos conteúdos técnicos e esportivos que eram desenvolvidos entre o período de 1960 a 1980 , limitado ao ambiente de funcionalidade técnico-profissionalizante demandado pela nova Reforma do Ensino Médio. Esse debate foi amparado por Santos, Santos Júnior e Ferreira (2017, p. 50), quando afirmam que:

Outro aspecto importante no campo da formação será a desvalorização/secundarização de conhecimentos relacionados às ciências humanas no currículo dos cursos de formação e, por conseguinte, à retomada da valorização das práticas técnicas esportivas muito comuns nas décadas de predomínio do tecnicismo na educação brasileira. Temos essa compreensão por entender que, em relação à $\mathrm{BNCC}$, o atual governo não buscará democratizar o debate, mas o tratará nos gabinetes do MEC. Portanto, tenderá a seguir a lógica de retomada do ensino tecnicista proposto na Lei 13.415/17, haja vista que o novo inciso $\left(\S 8^{\circ}\right)$ incluído no Art. 62 da LDB/96, determina que "os currículos dos cursos de formação de docentes 
terão por referência a Base Nacional Comum Curricular". Ou seja, a concepção de educação destinada para a educação básica determinará também a formação do professor.

Resende e Soares (1996) nos fazem recordar que, na década de 1970, era predominante nas escolas a promoção da aptidão física e a aprendizagem dos esportes. E a predominância desse tipo de pedagogia imposta nas aulas de Educação Física naquele período era baseada na ideia de que a população brasileira deveria frequentar a escola dos 7 aos 14 anos, cujo objetivo deveria ser a melhoria da condição física dos jovens e propagar a prática esportivizada, no sentido da massificação, e tão logo após a especialização precoce.

Com isso, a crença num discurso desenvolvimentista do esporte e da educação servia como um modelo a ser seguido. Andrade et.al (2007) nos fazem refletir sobre a realidade da esportivização:

Com tudo isso, o Brasil não se tornou uma potência olímpica, não reduziu as diferenças sociais, não melhorou a saúde da população, não diminuiu o acesso dos jovens às drogas e vícios e pior, não aumentou o número de adeptos as práticas corporais livres. Como o tempo, notou-se que a escola não era o lugar ideal para a produção de atletas e as instituições esportivas, criaram seus espaços próprios, mostrando a verdadeira face do esporte como fenômeno social, manter um produto que precisava de mão de obra e assim, seleciona, exige e disciplina o sujeito, por vezes afastando-o da escola em nome de um sonho e uma falsa expectativa de sucesso e ascensão social para todos. Para isso, houve seleção de pessoas de forma impessoal e sem considerar a diversidade corporal gerada pela cultura corporal de movimento de cada um, tal seleção era feita por base no biótipo, aspectos médicos, técnicas de avaliação biométricas, como estruturas musculares e a capacidade de adaptação a um ou outro tipo de treinamento, abrindo espaço para visões e testes excludentes, racistas, sexistas, para a seleção humana (ANDRADE, 2007, p. 1).

Já sob o ponto de vista da formação profissional, acredita-se que a Reforma do Ensino Médio também trará interferências para a Educação Física, poderá ocorrer a redução do espaço de trabalho nos ambientes escolares, visto que, as escolas terão autonomia na decisão de quais itinerários formativos irão ofertar. Sendo assim, dependerá das condições logísticas, econômicas, estruturais dos ambientes escolares. Caso, a escola não ofereça o itinerário formativo que englobe a disciplina de Educação Física denominado "Linguagens e suas Tecnologias", poderá haver uma redução dos postos de trabalho para esses profissionais, já que, antes era obrigatório a disciplina de Educação Física no Ensino Médio em todas as escolas, agora, para que os alunos exerçam a disciplina, os mesmos deverão optar pela área 
que a abrange. Isso posto, se a escola não oferta esse itinerário, é menos um espaço de trabalho para os educadores, além disso, poderá acarretar na redução dos cursos de graduação em Licenciatura na Educação Física, pois diminuindo os espaços de trabalho haverá mais profissionais no mercado e menos interesse da população em cursar Educação Física, o que poderá aumentar ainda mais a fragmentação entre esses dois campos de formação criando conflitos entre os profissionais da área.

O reordenamento no trabalho do professor de Educação Física trouxe à cena, uma série de questões referentes a essa profissão, mudanças no conteúdo do trabalho, aumento na precarização do trabalho, regulamentação da profissão e transformações no que se refere à formação profissional da área (COIMBRA, 2009, p. 64).

Segundo Silva (2009 citado po Rocha et.al 2019), o autor nos auxilia a compreender quanto à fragmentação do curso. $\mathrm{O}$ ensino superior vem se expandindo cada vez mais e no campo da Educação Física não é diferente. Os dados apontam um interesse considerável das instituições privadas nesta formação fragmentada, vislumbrando o crescimento do mercado vinculado às práticas corporais. O novo regime educacional que divide o campo da Educação Física, desprestigia e desvaloriza a luta por uma formação generalista competente, reforçando a alienação na formação para o trabalho, além disso, intensifica a divisão entre teoria e prática, público e privado, formação ampliada e formação especializada. A educação passa a estar cada vez mais constituída do discurso do lucro, da eficácia, da competitividade provenientes do sistema capitalista.

Dessa forma, conseguimos traçar relações entre a fragmentação do curso e a nova Reforma do Ensino Médio. A disciplina de Educação Física enfrenta com a Nova Reforma do Ensino Médio grandes dificuldades de legitimação e também de reconhecimento. A partir do que foi compreendido, conseguimos criar traços que mostram a realidade que será imposta com o novo Ensino Médio no currículo. Observamos que afetará a educação dos jovens, em especial, os mais pobres que se veem no preceito de frequentar as escolas públicas do Brasil. Não menos importante, é necessário ressaltar que a vida dos profissionais que escolheram a Educação Física, também entra em processo de precarização quando se faz referência ao trabalho, e infelizmente, as forças para interrupção das propostas governamentais ainda se encontram fragilizadas para romper as intenções políticas do governo. 


\section{Considerações Finais}

A reflexão desenvolvida acerca da problemática deste artigo nos auxilia a prever as consequências da nova Reforma do Ensino Médio na educação, e em especial na disciplina de Educação física. A nova lei tem como perspectivas que os alunos possam ter maiores oportunidades com o trabalho e as escolas também iriam se adequar a funcionalidade do mercado de trabalho.

Observamos que a indicação da nova lei trata-se de uma contrarreforma que desconsidera o acúmulo de conhecimentos e discussões. Ademais, sabe-se da importância da educação para o caráter formativo de um aluno, no entanto, as ações do governo brasileiro não buscam uma formação crítica e humanística.

Consideramos que existem várias possibilidades para intervir e aprender agindo diretamente na realidade social, por meio da disciplina de Educação Física. Os professores possuem um papel importante, assim sendo, devem buscar uma práxis estabalecendo relação intrínseca entre os conhecimentos científicos e individuais da cultura corporal, considerando o aluno como ser sócio-histórico.

A busca de uma Educação Física crítica, com vista às novas possibilidades de desenvolver as potencialidades de cada aluno, implica pensar uma disciplina que inclua as práticas corporais, respeitando as capacidades e habilidades de cada jovem educando no seu ritmo e tempo de aprendizagem. Dessa maneira, mais importante que o desenvolvimento da performance e da aptidão é ter um ambiente harmonioso e construtivo, no qual, o aluno se desenvolva via cultura corporal. Não pretendemos defender o fim do desporto nas aulas, e sim que a sua prática seja realizada de forma a despertar a criticidade para despertar também a capacidade de se desvincular de padrões estéticos de beleza propostos pelos meios midiáticos e pelo mercado capitalista.

Por fim, torna-se preciso salientar a importância da disciplina de Educação Física no currículo, visto que, a mesma possui seu papel formador na vida dos alunos. A disciplina vai muita além de práticas esportivas possuindo dentro de suas características um leque de oportunidades que estimulam o processo de ensino-aprendizagem. Diante disso, precisamos lutar pela Educação, e para que todos os indivíduos internos e externos ao meio escolar, possam compreender a importância da Educação Física dentro do currículo escolar.

\section{Referências}


ANDRADE, Rogério Pinheiro dos Santos. Ação Docente Critica em Educação Física Escolar Revendo as Práticas e as Finalidades Por Uma Educação Física Crítico / Desportiva. XI EnFEFE - Encontro Fluminense de Educação Física Escolar. Disponível em: $<$ http://cev.org.br/biblioteca/acao-docente-critica-educacao-fisica-escolar-revendo-aspraticas-as-finalidades-por-uma-educacao-fisica-critico-desportiva> Acessado em: 17.mar.2020.

ANTUNES, Ricardo. Trabalho e precarização numa ordem neoliberal. In: GENTILI, Pablo; FRIGOTTO, Gaudêncio, A cidadania negada: Política de exclusão na educação e no trabalho. Coleção Grupos de Trabalho, CLACSO. Buenos Aires: CLACSO, 2000. p. 35-46.

BRASIL. Lei de Diretrizes e Bases da Educação Nacional. Lei n ${ }^{\circ} 13.415 / 2017$, de 13 de fevereiro de 2017, Altera as Leis nos 9.394, de 20 de dezembro de 1996, que estabelece as diretrizes e bases da educação nacional, e 11.494, de 20 de junho 2007, que regulamenta o Fundo de Manutenção e Desenvolvimento da Educação Básica e de Valorização dos Profissionais da Educação, a Consolidação das Leis do Trabalho -CLT, aprovada pelo Decreto-Lei no 5.452, de 1o de maio de 1943, e o Decreto-Lei no 236, de 28 de fevereiro de 1967; revoga a Lei no 11.161, de 5 de agosto de 2005; e institui a Política de Fomento à Implementação de Escolas de Ensino Médio em Tempo Integral. 2017.

BRASIL. Ministério da Educação. Secretaria de Educação Básica. Conselho Nacional de Educação. Base Nacional Comum Curricular: educação é a base. Brasília: MEC ; SEB; CNE, 2017.

CBCE. Nota de repúdio. Diretoria Nacional do Colégio Brasileiro de Ciências do Esporte;. Curitiba,PR,23set.2016.Disponível <http://www.cbce.org.br/upload/files/NOTA_REPUDIO_CBCE_1.pdf>. Acesso em: 05.dez.2019.

COIMBRA, Tatiane Carneiro. O reordenamento no mundo do trabalho e a precarização do trabalho do professor de educação física: mediações da mercadorização da cultura corporal. Dissertação Universidade Federal Fluminense - Educação, 2009.

COSTA, Maria Adélia. O notório saber e a precarização da formação docente para a educação profissional. Revista Profissão Docente, v. 18, n. 39, p. 239-254, 2018.

FAE. Texto para discussão: Reforma do Ensino Médio - MP 746/2016. UFMG: Belo Horizonte, 2017. Disponível em: < https://observatoriodajuventude.ufmg.br/texto-paradiscussao-reforma-do-ensino-medio-mp-7462016/>. Acesso em 03.jan.2020.

FERREIRA, Eliza Bartolozzi. A contrarreforma do ensino médio no contexto da nova ordem e progresso. Educação e Sociedade, Campinas, v. 38, n. 139, p. 293-308, June 2017. Disponível em: <http://www.scielo.br/scielo.php?pid=S010173302017000200293\&script=sci_abstract\&tlng= pt> Acesso em 15.jan.2020.

FRIZZO, Giovanni. A REFORMA DO ENSINO MÉDIO E OS INTERESSES DE MERCADO NA POLÍTICA EDUCACIONAL. Poiésis-Revista do Programa de PósGraduação em Educação, v. 10, n. 17, p. 215-224, 2016.

GARIGLIO, José Ângelo; JUNIOR, Admir Soares Almeida; OLIVEIRA, Cláudio Márcio. O "novo" Ensino Médio: implicações ao processo de legitimação da Educação Física. 
Motrivivência, v. 29, n. 52, p. 53-70, 2017. Disponível em: $<$ http://www.scielo.br/scielo.php?pid=S010173302017000200293\&script=sci_abstract\&tlng $=\mathrm{pt}>$. Acesso em 24.jan.2020.

GOMIDE, Denise Camargo; JACOMELI, Maria Regina Martins. NOTÓRIO SABER: DESREGULAMENTAÇÃ̃O DA FORMAÇÃO DOCENTE NA LEI DA REFORMA DO ENSINO MÉDIO. Anais, 2017. Disponível em: http://anaisbr2017.redeestrado.org/files/abstracts/000/000/597/original/GOMIDE_E_JACOM ELI_-_TRABALHO_COMPLETO.pdf. Acessado em 19 de jul.2020.

JÚNIOR, José Ribamar Ferreira et al. Reforma do ensino médio, qual o lugar da educação física?. XX Conbrace VII Conice. Goiânia-GO, 2017. Disponível em: < http://congressos.cbce.org.br/index.php/conbrace2017/7conice/paper/viewFile/9925/4928>. Acesso em 18.jan.2020.

LINO, Lucilia Augusta. As ameaças da reforma desqualificação e exclusão. Revista Retratos da Escola, Brasília, DF, v. 11, n. 20, p. 75-90, 2017. Disponível em: < http://retratosdaescola.emnuvens.com.br/rde/article/view/756> Acesso em 30.jan.2020.

MATOS, José Arlen Beltrão. Novo ensino médio: o rebaixamento da formação, o avanço da privatização e a necessidade de alternativa pedagógica crítica na educação física. Tese (Doutorado em Educação), Universidade Federal da Bahia. Faculdade de Educação, Salvador, Bahia, 2019.

MORAES, Roque; GALIAZZI, Maria do Carmo. Análise discursiva textual: processo reconstrutivo de múltiplas faces. Ciênc. educ. (Bauru), Bauru, v. 12, n. 1, p. 117-128, abril de 2006. Disponível em: <http://www.scielo.br/scielo.php?script=sci_arttext\&pid=S1516$73132006000100009 \& \operatorname{lng}=\mathrm{en} \& \mathrm{nrm}=\mathrm{iso}>$. acesso em 20.jul.2020.

NOZAKI, Hajime Takeuchi. Educação física e o reordenamento do mundo do trabalho: mediações da regulamentação da profissão. Tese (Doutorado em Educação) - Universidade Federal Fluminense; Niterói, Rio de Janeiro, 2004.

OLIVEIRA, Dalila Andrade. A reestruturação do trabalho docente: precarização e flexibilização. Educação \& Sociedade, v. 25, n. 89, p. 1127-1144, 2004.

OLIVEIRA, Inês Barbosa de. O objetivo da reforma do ensino médio é reproduzir a exclusão social. [Entrevista concedida a] Beatriz Mota e André Antunes. Escola Politécnica de Saúde Joaquim Venâncio - FioCuz. Abril, 2019. Disponível em: <http://www.epsjv.fiocruz.br/noticias/entrevista/o-objetivo-da-reforma-do-ensino-medio-ereproduzir-a-exclusao-social>. Acessado em 05.dez.2019.

OLIVEIRA, Márcia Soares de; DA COSTA, Maria Adélia. A educação profissional e a lei no 13.415-2017: uma ponte para o passado. IV Colóquio Nacional e I colóquio internacional a Produção do Conhecimento em Educação Profissional, Natal, Rio Grande do Norte, 2017.

OLIVEIRA, Priscila Borges de. Reforma do ensino médio: o espaço da arte no currículo. Trabalho de Conclusão de Curso ( Licenciatura no curso de Artes Visuais) - Universidade do Extremo Sul Catarinense - Unesc; Criciuma, 2017.

RAMOS, Flávia Regina Oliveira; HEINSFELD, Bruna Damiana de Sá Sólon. Reforma do Ensino Médio de 2017 (lei $\mathbf{n}^{\mathbf{0}}$ 13.415/2017): um estímulo à visão utilitarista do conhecimento. In: XIII EDUCARE-Congresso Nacional de Educação. 2007. p. 18284-18300. Disponível

em: 
<https://www.researchgate.net/publication/320265714_Reforma_do_Ensino_Medio_de_2017 _Lei_n_134152017_um_estimulo_a_visao_utilitarista_do_conhecimento> Acesso em 22.fev.2020.

RAMOS, Marise Nogueira; FRIGOTTO, Gaudêncio. Medida Provisória 746/2016: a contrareforma do ensino médio do golpe de estado de 31 de agosto de 2016. Revista HISTEDBR On-line, v. 16, n. 70,p. 30-48, 2016.Disponível em: < https://periodicos.sbu.unicamp.br/ojs/index.php/histedbr/article/view/8649207>. Acesso em 01.mar.2020.

RESENDE, Helder Guerra de; SOARES, Antônio Jorge Gonçalves. Conhecimento e especificidade da educação física escolar, na perspectiva da cultura corporal. Revista Paulista de Educação Física, p. 49-59, 1996. Disponível em: < http://citrus.uspnet.usp.br/eef/uploads/arquivo/v10\%20supl2\%20artigo9.pdf> Acesso em: 05.fev.2020.

ROCHA, Bruna Beatriz da; DOS SANTOS COELHO, Fernanda Cristina; TOLEDO, Flaviana Alves. Licenciatura e bacharelado em educação física: impactos na formação profissional no estado de Minas Gerais. REVES-Revista Relações Sociais, v. 2, n. 1, p. 0103-0118, 2019. Disponível em: <https://periodicos.ufv.br/reves/article/view/3216> Acesso em: 03.fev.2020.

SANTOS, Núbia Gonçalves de; SOUZA, Luís César de. INTERESSES POLÍTICOECONÔMICOS DE SETORES PRODUTIVOS E A (DE) FORMAÇÃO DECORRENTE DA ATUAL REFORMA DO ENSINO MÉDIO. Anais da Semana de Licenciatura, v. 1, n. 9, p. 248-253, 2019.

SANTOS, Robson Bastos dos; SANTOS JUNIOR, Osvaldo Galdino dos; ALMEIDA FERREIRA, Marcelo Pereira. Reforma do Ensino Médio e a Educação Física: um abismo para o futuro. Motrivivência, v. 29, n. 52, p. 38-52, 2017.

TEIXEIRA, Rosane de Fátima Batista et al. Concepções de itinerários formativos a partir da Resolução CNE/CEB No 06/2012 e da Lei No 13.415/2017. Educação no Século XXIVolume 28 Gestão e Políticas Públicas, p. 59, 2017.

TURATO, Egberto Ribeiro. Tratado da metodologia da pesquisa clínico-qualitativa: construção teórico-epistemológica, discussão comparada e aplicação nas áreas da saúde e humanas. 2. ed. Petrópolis. Vozes, 2003. 